But he has, at all events, laid those who are interested in cytological development under a debt of gratitude by the exhaustive treatment he has accorded to those topics which he decided to discuss.

\section{MARINE PROPELLERS.}

The Screw Propeller: and other Competing Instruments for Marine Propulsion. By A. E. Seaton. Pp. xii+255. (London: Charles Griffin and Co., Ltd., I909.) Price i2s. $6 d$. net.

THE author of this book is well known, both as 1 a practising marine engineer and as an author. His "Manual of Marine Engineering" has long served as a text-book, and has passed through many editions. It was natural, therefore, that the announcement of a work by Mr. Seaton dealing with marine propellers should awaken interest over a wide circle of readers, more especially as the problem of propeller design has not yet received a complete solution. As Mr. Seaton says, "even in modern times.... our best men do sometimes fail to achieve success," although there are now available the results of much experimental and theoretical investigation on the subject. After seventy years' continuous work it still remains true that when novel types of ships or unprecedented speeds have to be attempted, although use may have been made of all available data, and the best advice taken, full success is not always or at once achieved. On the contrary, considerable gains in efficiency are frequently attained by a process of " trial and error," out of which comes a final selection of the propeller forms and dimensions best suited to novel conditions.

Such a confession may be thought discreditable; indeed, it is sometimes so treated by critics who have not themselves had occasion to undertake responsibility for ship and propeller designs; but it represents the facts of the case, and the explanation is not far to seek. When a problem has been unsuccessfully attacked by men like Rankine and William Froude, amongst those who have finished their work, and by men like R. E. Froude, Cotterill, Greenhill, and D. W. Taylor, who are still alive and interested in finding solutions, it may be presumed that the problem involves considerable difficulties. When one considers the almost endless variety of the conditions involved in ship propulsion, the failure to reach a complete solution of the problem need not cause astonishment, and it is reasonable to anticipate that we shall have to be content for some time to come, if not permanently, with partial solutions chiefly based on experimental investigations, and on careful scientific analyses of the results.

$\mathrm{Mr}$. Seaton definitely states in his preface that the

" object of the present work is to amplify and extend what [had been given] in skeleton or in rudimentary form "(in his "Manual of Marine Engineering") in the shape of rules for guidance in the practical work of designing propellers. These rules are said to have been "generally based on scientific reasons and always capable of giving results agreeable with the best and most successful practice": and it is claimed that by means of successive improvements "they NO. 2077 , VOL. 81$]$ have become generally applicable to the design of a screw for an Atlantic liner or a torpedo boat." It is added that "the more abstruse and highly mathematical investigations connected with the theory of the resistance of ships and propellers have been left to be studied in the text-books and .... valuable papers " of various authors.

More or less empirical rules such as Mr. Seaton proposes no doubt have a certain value as representing his own practice and deductions from his study of published results of steamship trials, but it cannot be admitted that such rules can be depended upon absolutely when new conditions have to be faced. If it were true that the best results could be ensured by the use of any known rules in the designs of screws over the wide range from " an Atlantic liner to a torpedo boat," difficulties such as have been mentioned would disappear, and the work of the naval architect would become easy of performance. The occurrence of these difficulties demonstrates the imperfection of existing rules.

Turning to the general scheme of the book, it may be said that the section dealing with the history of marine propellers is both interesting and valuable. Bourne's book, giving the early history of the screw propeller, is not now generally accessible, and $\mathrm{Mr}$. Seaton's summary will be found useful for reference. Paddle wheels, screws, and hydraulic (or jet) propellers are treated separately, their principles of action are explained, rules being given for their practical design. One chapter is devoted to an explanation, in popular language, of the modern theory of the resistance of water to the motion of ships, but readers desiring full information on the subject will necessarily have to turn to other sources, as Mr. Seaton only attempts a brief sketch. Naturally, screw propellers claim most attention, their various forms, numbers and positions are described; and the effects of changes in numbers, shape, and proportions of blades are also discussed at some length. Much information has been collected and collated respecting experimental trials made with screw propellers, but it seems doubtful whether the large amount of space devoted to trials made by the Admiralty and other experimentalists in the early period of screw propulsion might not have been better utilised, seeing that these trials were made on ships the forms, proportions, and speeds of which in no way represent present practice, while many important conditions affecting results are not definitely known. An antiquarian interest attaches to them, and from their consideration certain useful deductions may be, and, indeed, have been, made; but radical differences exist between conditions prevailing thirty or forty years ago and those of the present day, and the devotion of much time to this subject, when better and later information is available, is not desirable. The chapters dealing with the geometry of the screw and materials used in the construction of the screw propeller are excellent.

The book is well produced and illustrated. It has an excellent index, and as a work of reference will be found of service to all interested in the propulsion of ships. 